\title{
МОБИЛЬНАЯ ЗАНЯТОСТЬ МОБИЛЬНОГО СУБЪЕКТА
}

Статья посвящена анализу трудовых траекторий мигрантов из Средней Азии, прибывших в российские мегаполисы с целью заработка. В исследовании седентаристская оптика сменяется мобильной, и трудовая активность гастарбайтеров интерпретируется через понятие мобильности. С этой целью введен концепт «мобильного субъекта», среди специфических черт которого подвижность, нестабильность, множественность жизненных проектов, жизнь в «сиюминутном» времени, автономизация и в то же время формирование широкой сети социальных контактов, отказ от интеграции. Исследование выполнено в рамках качественной методологии, основные методы- интервьюирование и наблюдение. В фокусе исследования около 30 кейсов. В тексте в качестве иллюстраций рассматриваются три кейса-жизненные истории мигрантов из Таджикистана и Кыргызстана. Исследование было лонгитюдным, в течение пяти лет каждые полгода мы встречались с информантами, что позволило проанализировать сложные биографические траектории людей, в частности, изменение их трудовых стратегий. В связи со структурными изменениями на новом месте жительства мигранты, как правило, занимают ниши низкоквалифицированного труда. Меняя национальные контексты, мобильный субъект зачастую начинает трудовую карьеру «с нуля», не подтверждая прежнюю квалификацию. Анализ биографий информантов демонстрирует нелинейность и изменчивость их трудовых траекторий. Согласно исследованию, гастарбайтеры работают в нескольких местах одновременно; реализуют себя в рамках разных профессиональных сфер; сочетают разные формы занятости; не привязаны к одному месту работы. Трудовые траектории мигрантов не представляют собой линейную карьеру как целенаправленное движение в рамках одной профессии или одной организации. Карьера мобильного субъекта

Ольга Евгеньевна Бредникова- к.с.н, ведущий научный сотрудник, Центр независимых социологических исследований, Санкт-Петербург, Россия. Электронная почта: brednikova@cisr.ru 
экстенсивна- мигрант накапливает самые разнообразные опыты, меняя места работы и профессиональные сферы, сочетая разные формы занятости, что позволяет мигрантам быть мобильными, реактивно приспосабливаться к меняющемуся рынку труда и изменяющимся структурным условиям. Смена исследовательской оптики открывает новую перспективу в понимании мигрантского труда и позволяет увидеть в нем не только проблемы (прекарность, нестабильность, (само-)эксплуатацию и пр.), но и агентность в выборе трудовых стратегий.

Ключевые слова: мобильный субъект, миграция из Средней Азии, жизненные траектории, трудовая карьера и трудовые стратегии, прекарность

DOI: $10.17323 / 727-0634-2020-18-4-705-720$

Mobilis in mobile - девиз капитана Немо из произведения Жюля Верна, который, по мнению автора предисловия к русскоязычному изданию книги Джона Урри, прекрасно характеризует современные общества (Урри 2012:7). Глобальные и видимые изменения современных социальных реалий вызвали мобильный поворот в социальных исследованиях, связываемый прежде всего с идеями Урри (Урри 2012), концепциями общества потоков Кастельса (2002), «детерриториализации» и «номады» Делеза и Гваттари (Deleuze, Guattari 1986), текучей современности Баумана (2008). Эти концепции не только обозначают смену исследовательского фокуса с «человека укорененного» на «человека двигающегося» и отказ от седентаристской оптики, в рамках которой оседлость рассматривалась как своего рода социальная норма (Vertovec 2007), но и смену исследовательской тематики и методологии, что сделать в академических исследованиях, как оказалось, не так-то просто, ибо всегда есть большой соблазн интерпретировать передвижение людей как конечный процесс. То же справедливо и в отношении анализа трудовой активности мигрантов. Давняя традиция исследовать предпринимательскую активность мигрантов, которая ранее интерпретировалась как этническая экономика (Light, Gold 2000; Уолдингер и др. 2008), а сейчас, скорее, как мигрантская (Бредникова, Паченков 2002; Edwards et al. 2016), демонстрирует не просто спецификацию предпринимательской практики, в которую вовлекаются мигранты, но и предлагает основание для этой спецификации. В качестве границы выступает «чужой» (этническая экономика) или «пришлый» (мигрантская экономика). Справедливости ради следует признать, что современные исследования подвергают сомнению наличие особых предпринимательских навыков у мигрантов и, более широко, существование какой-либо специфики предпринимательской активности среди мигрантов (Nuade et al. 2017) или же переносят фокус внимания на структурные условия, порождающие предпринимательскую активность (см.: Пешкова 2018). 
В этой статье я интерпретирую трудовую активность мигрантов через понятие мобильности и показываю, что изменчивость и нестабильность встроена в мобильность, выступает в качестве ценности или желаемого состояния. По сути, они конституируют мобильного субъекта и определяют его трудовые траектории и практики. В фокусе исследования- мигранты из Кыргызстана, Таджикистана и Узбекистана, прибывшие в Москву и СанктПетербург с целью заработка. Исследование проводилось в логике кейс-стади (всего около 30 кейсов), и участники проекта общались не только с ключевыми информантами-мигрантами, но и с их окружением, прежде всего с членами семей, оставшимися дома. Исследование лонгитюдное. Каждые полгода мы встречались с ключевыми информантами, что позволило отследить биографические траектории людей со всеми поворотами и жизненными коллизиями, что, пожалуй, дало самый богатый материал.

\section{Мобильность мобильных}

Мобильный субъект и сам феномен мобильности очень подвижны. И этот тезис не тавтология или игра слов. Исследователи фиксируют быстрые и значительные изменения в феномене миграции. Пожалуй, наиболее важные изменения связаны с тем фактом, что иммиграция (как переезд из одного места жительства в другое) и трудовая миграция перестают быть доминирующими миграционными сценариями, в частности распространены климатические миграции, когда фрилансеры едут «перезимовать» в теплые страны, миграции пенсионеров, которые стремясь сохранить прежний уровень жизни при уменьшении размеров доходов, меняют национальные контексты. Важно заметить, что ранее типологии миграций выстраивались на основании причин и целей перемещений. Сейчас же цели миграций имеют смешанный характер либо не определены вовсе. Появившееся не так давно понятие «миграции как образа жизни», отражающее феномен «движения к лучшей жизни», объединяет в себе миграции досуга, контрурбанизацию и «сельскую идиллию», вторичное домовладение и пр. (Benson, O’Reilly 2009:2). И даже причины и цели трудовой миграции не так однозначны: например, молодежь, приезжающая из Средней Азии в российские города «на заработки», реализует не только сценарий «гастарбайтера». Зачастую они осуществляют приключенческий сценарий, который связан не столько с желанием заработать, сколько получить впечатления и опыт, посетить новые места и сформировать новый круг общения (Бредникова 2017:35).

Изменение связано с направлениями перемещений. Ныне миграции разнонаправленны, люди передвигаются во всех направлениях по всему миру. И это не линейное перемещение из одного места в другое. Современные номады не следуют строго фиксированным маршрутам, их движение не происходит между отправляющими и принимающими обществами, в которых они задерживаются на длительное время. Мигранты 
двигаются по слабоструктурированным траекториям, речь идет, скорее, о некой циркуляции между «точками» или локациями временных остановок (Kalčić 2013).

В движение вовлечены самые разные социальные группы. Однако несмотря на его богатство и разнообразие возможно выделить общие черты, которые помогают обозначить специфику вовлеченных в него агентов. Так, можно говорить о мобильном субъекте. Само понятие «мобильный субъект» не часто встречается в академических дискуссиях. Возможно, номинации самого явления и его участников еще кристаллизуются, о чем говорит целый репертуар вариантов- «номады», «ведущие высокомобильный образ жизни», «странники» и пр. (см., Kalčić 2013). Однако в данном исследовании представляется уместным использование понятие «мобильного субъекта», под которым я буду понимать индивидов, для кого миграции «мыслимы, осуществимы и желаемы» (Biao 2007: 70), они «естественным образом» встроены в жизненные проекты и траектории. Мобильность выступает основной конституирующей чертой субъекта- мыслящего и действующего, при этом перманентно перемещающегося. Приведу характеристики, которые, на мой взгляд, важны не только для понимания специфики мобильного субъекта, но и для интерпретации его/ее трудовой активности.

Мобильность. Для мобильного субъекта движение- смыслообразующая практика и основная жизненная стратегия. Наше лонгитюдное исследование позволило зафиксировать этот факт. Мигранты не только перемещаются в пространстве, но быстро и кардинально меняют свою жизнь, регулярно меняя работу, местожительство, обновляя сети поддержки и прочее. Ответом на любые вызовы, на изменение структурных условий и биографических контекстов становится мобильность. Наши информанты в течение полугода могли «уехать домой навсегда» с тем, чтобы спустя месяц вернуться, поменять сферу занятости, сменить сексуальных партнеров.

Множественность жсизненных проектов. Мобильный субъект одновременно реализует целый репертуар жизненных проектов, при этом инвестируя во всевозможные сценарии в расчете на то, что один из них обязательно сработает как наиболее приемлемый. Например, мой информант одновременно вкладывает деньги в строительство дома на родине, рассчитывая со временем вернуться, оформляет российское гражданство с тем, чтобы остаться в РФ, в то же время собирает информацию о возможной миграции в Швецию.

«Сиюминутное время» мигрантов. Зигмунт Бауман, сравнивая «текучую современность» с «твердой модерностью», писал о сиюминутном времени (Бауман 2008: 135-140), специфика которого, помимо прочего, связана с концентрацией времени в настоящем. То же можно сказать и о специфике времени мобильного субъекта, которую можно охарактеризовать как «длительную временность». С одной стороны, он(а) реализует краткосрочные 
жизненные проекты с конкретными целями-свадьба, строительство дома и прочее. С другой стороны, цели сменяют одна другую, цепляются друг за друга, и миграция оказывается длительной, несмотря на краткосрочность жизненных проектов.

Такая временность может длиться годами и десятилетиями, границы которой не определены. Мобильный субъект, концентрируясь в сиюминутном времени, оказывается вне прошлого и будущего, ибо они выносятся за границы настоящей, «сиюминутной» жизни. Прошлое отдаляется и почти не связано с тем, что происходит в настоящем, а будущее зачастую не сформировано и/или детерриториализированно. Такое будущее локализуется за пределами миграции, появляется там, где, возможно, она закончится. При этом сию минуту сама миграция не имеет сколь-либо точного окончания.

Автономизация и «отказ» от интеграции. Интеграция все чаще определяется в связи с опытом общей автономизации и выстраиванием новой субъектности (Slany et al. 2010). Отношение к миграции как временному проекту способствует тому, что мобильный субъект интегрируется в принимающее общество лишь в тех масштабах и сферах, где это актуально «здесь и сейчас». Его интеграцию следует рассматривать как процесс (постоянное движение); как фрагментированный процесс (можно интегрироваться в одни сферы жизни и отказываться от интеграции в другие); как процесс «без конца» (без конкретного результата); и как разнонаправленный процесс (можно говорить не только об интеграции, но и о процессе дезинтеграции, например, в связи со сменой миграционного сценария).

Широкие и слабые социальные сети. Мобильный субъект вынужден вести активную сетевую работу: в ситуации миграции его социальный капитал крайне мал, он оказывается очень востребованным для обретения новых компетенций и встраивания в новые контексты. Сети мобильного субъекта неустойчивы, подвижны, ситуативны. Они выстроены отнюдь не на условно традиционных основаниях (семья, землячество, этничность). Основания для солидарности и выстраивания сетей могут быть множественные. Наиболее крепкие и актуальные связи выстраиваются на основании общего опыта и с теми, кто разделяет стили жизни (Kalčić 2013).

Этот далеко не полный и актуальный для лишь исследуемой темы перечень характеристик мобильного субъекта, на мой взгляд, задает важную перспективу понимания специфики трудовой активности мигрантов, которая рассмотрена ниже.

\section{Трудовые траектории трудовых мигрантов}

Трудовая активность не становилась специальным фокусом моих исследований мигрантов из Средней Азии. Однако именно смещенный фокус и разговоры с информантами на самые разные темы о жизни в миграции 
дали богатый материал для понимания их трудовой активности. Такие биографические нарративы имеют свою специфику (Breckner 2014). Жизненная траектория в биографических повествованиях мигрантов являет собой непоследовательное движение из одного «возраста жизни» в другой или процесс изменения социальных статусов. Биография, рассказанная моими информантами,-это прежде всего трудовая биография. Она выглядит как перечисление мест, где бывал мигрант, в связке с перечислением мест, где он работал. Зачастую такой нарратив не выстроен хронологически, а представляет собой некую копилку мест жительства и мест работы. Чем больше стаж миграции, тем «полнее копилка». Биография мобильного субъекта представлена не как расширение своего жизненного пространства, наращивание социальных сетей или изменение статусов, но как коллекция разных опытов.

Далее я коротко опишу трудовые биографии трех информантов- мигрантов из Средней Азии, работающих в Санкт-Петербурге. Эти кейсы, с одной стороны, типичные- такие жизненные траектории очень распространены, с другой стороны, выбранные истории очень иллюстративны, ибо вобрали в себя разнообразие и возможную вариативность.

Манас- мигрант из Кыргызстана, из пригорода Оша, ему 45 лет. У Манаса высшее образование, на родине он работал стоматологом. Приехал в Санкт-Петербург около десяти лет назад вместе с женой и младшим сыном. По приезде Манас работал охранником в магазине, затем устроился работать на производство, где занимался выпечкой печенья и сдобы. Согласно рассказам информанта, его там обманывали, и работа была изнуряющая, в ночную смену. Манас на какое-то время уезжал к родственникам в Якутию, где работал на рынке. Потом он решил вернуться в Петербург. Причины таких кардинальных переездов информант не обговаривал. В Петербурге он нашел место охранника в магазине детских товаров. В интервью Манас долго и подробно рассуждал о хороших условиях труда в магазине, об удобном графике работы и о несложных обязанностях: «Я всегда в белой рубашке работаю».

В выходные и по вечерам Манас работает стоматологом, лечит зубы знакомым, по его словам, «своим». Информант уточнил, что среди клиентов не только кыргызы, но есть знакомые и «знакомые знакомых» из Таджикистана. Инструменты и материалы Манас получает из дома. Представляется интересным, что информант не счел нужным сразу рассказать про эту работу. Возможно, он интерпретирует ее как не совсем легальную, о чем «не стоит говорить», и статус этой трудовой деятельности для Манаса иной, нежели «основная» работа охранником. Важно, что ему удалось использовать профессиональный опыт на новом месте, пусть и не в полной мере. При этом Манас не стремится сфокусироваться и сделать карьеру в рамках профессии, полученной дома, но реализует себя в разных сферах.

Нодира- мигрантка из Узбекистана, ей 39 лет. Нодира из небольшого города, имеет высшее экономическое образование. В Петербурге около 15 лет. 
Дома Нодира работала бухгалтером, но «зарабатывала копейки» и потому решила уехать в Россию. По приезде Нодира, не пытаясь искать работу по специальности, довольно быстро нашла место в клининговой компании и несколько лет работала в фитнес-клубе уборщицей. На момент нашей последней встречи информантка ушла из этой компании из-за трудового конфликта. Причиной конфликта, по словам женщины, стала задержка зарплаты. Нодира стала работать частным образом, она убирает квартиры. Следует отметить, что Нодира- очень общительный человек, целенаправленно ведет сетевую работу, заводит знакомства, внося всех «новичков» в список контактов телефона, формируя таким образом клиентскую базу. Важно отметить, что Нодира интерпретирует свой переход от наемного труда к самозанятости как «освобождение от» (эксплуатации и финансовых обманов) и «освобождение для» (выстраивания своего графика работы, для поиска «приятных клиентов»).

Рахмонбек- мигрант из Таджикистана, из села из-под Душанбе, ему 35 лет. Рахмонбек в иммиграции около 10 лет, профессионального образования не имеет. После окончания школы «подрабатывал у друзей», ремонтировал машины. Затем по примеру одноклассников поехал на заработки в Петербург, где знакомые предложили ему работу в маленьком городке Ленобласти. Сначала информант работал там дворником, затем в ларьке продавцом «у хозяина». Рахмонбек довольно быстро женился на россиянке, родилась дочь. Они вместе с женой занимались мелким бизнесом- держали свой продуктовый ларек. Благодаря женитьбе Рахмонбек получил российское гражданство, что позволило ему впоследствии оформить статус индивидуального предпринимателя.

Информант рассказал, что мать настояла, чтобы он развелся и женился на женщине из Таджикистана. С новой женой Рахмонбек переехал в СанктПетербург. В этом браке родилось еще трое детей. В Петербурге Рахмонбек работал водителем маршрутки, потом таксистом. Затем информант уезжал ненадолго в Швецию, работал поваром в кафе у земляка. Однако что-то пошло не так, и Рахмонбек вернулся в Россию. Он избегал рассказов об этом опыте, который, возможно, связан с нелегальными практиками или расценивается как неудачный. После этого работал у приятеля на производстве, где делают клей. На момент последней встречи Рахмонбек с партнером-земляком держал свою пекарню и параллельно подрабатывал таксистом, выполняя мелкие заказы от знакомых. Информант жаловался на проблемы работы вдвоем, планировал отделиться от компаньона и заняться продажей мяса в Ленобласти.

В данном случае Рахмонбек демонстрирует сложную трудовую траекторию: довольно высокую мобильность, как в сфере трудовой деятельности (торговля, производство, частные услуги), так и в ее формах (наемный труд, самозанятость и мелкое предпринимательство). Он открыт новым опытам, готов и дальше менять место работы и жительства в поисках наиболее подходящих для себя условий. 


\section{Трудовая карьера мобильного субъекта}

Описанные примеры траекторий мигрантов позволяют увидеть закономерности в трудовой активности и стратегиях занятости мобильного субъекта. Мало кому из информантов удалось перенести в место миграции прежнюю профессиональную квалификацию и опыт. Лишь Манас реализует себя в рамках полученной дома профессии- работает стоматологом, при этом рассматривая эту деятельность как подработку. В новых национальных контекстах он никак не сертифицирует и не декларирует свою профессию, и в качестве клиентов выступают его земляки или люди со схожим опытом - такие же мигранты, для которых частная рекомендация важнее и актуальнее, чем сертификат врача. Местом работы Манаса стал импровизированный стоматологический кабинет- угол комнаты обыкновенной петербургской квартиры, в которой есть специальные медицинские инструменты и материалы, привезенные из Кыргызстана. Такая комбинация вещей и практик превращает кабинет в особое транснациональное пространство. И в этих новых контекстах трудовая деятельность Манаса наделяется новыми смыслами и значениями- она легитимна лишь в своей среде и рассматривается как дополнительная, хотя доход от нее вполне сопоставим с доходом от основной работы.

Случай Манаса- единичный пример. Очень редко встречаются информанты, которые продолжают трудовой путь в рамках профессии, приобретенной дома. Чаще мигранты осваивают новые профессиональные навыки. Трудовая ниша низкоквалифицированного труда, в которую включаются мигранты в соответствии со структурными условиями, в которые они попадают, позволяет им довольно быстро профессионализироваться в новой для них сфере. Как правило, мигранты трудятся в нескольких местах или используют максимум возможностей в рамках одного места работы. Так Нодира, работая в фитнес-клубе, постоянно искала возможности частных подработок по уборке квартир среди посетителей. Подобное сочетание работы по найму и самозанятости-самая распространенная комбинация форм трудовой активности. Формы занятости могут меняться с течением времени. Переход к самозанятости и предпринимательской активности отчасти связан со стажем миграции и процессами интеграции, ибо чем больше мигрантский стаж, тем больше социальный капитал, тем более мигрант эмансипируется и субъективируется в своей трудовой деятельности. Однако выбор трудовой стратегии продиктован выбором миграционного сценария. Для мигранта-гастрабайтера жизнь разворачивается вокруг трудовой активности. Мигрант, реализующий приключенческий сценарий, едет не только заработать, но и получить новые впечатления. Со сменой сценариев будут меняться и время, отведенное на трудовую активность, и формы занятости, и их комбинации. Таким образом, трудовая карьера мобильного субъекта-это не линейное 
движение, она меняет свою траекторию в связи со сменой структурных условий и биографических контекстов.

Множественность трудовых практик мобильного субъекта, связана с работой в разных профессиональных сферах. Рахмонбек зарабатывает, продавая выпечку и занимаясь извозом. Он варил клей, убирал улицы, готовил. Такое разнообразие связано не только с максимизацией доходов. Здесь прочитывается попытка эффективного распределения сил и возможностей, а также своего рода страховка от рисков в связи с общей нестабильностью положения мигранта. Безусловно, такой подход не уникален и характерен не только среде мигрантов. Однако здесь есть своя специфика, связанная с мобильностью. С одной стороны, это готовность мигрантов к движению и открытость новым опытам, в том числе и профессиональным; с другой- особая ниша низкоквалифицированного труда, которая не требует специальной квалификации или длительной подготовки. Таким образом, трудовая траектория мобильного субъекта представляет собой не движение по пути специализации и профессионализацию в рамках одной сферы, но аккумулирование разных профессиональных навыков в разных сферах. Разнообразие опыта и открытость к переменам позволяют реактивно приспосабливаться к изменяющимся условиям.

Как отмечалось выше, мобильный субъект живет в сиюминутном времени и реализует краткосрочные жизненные проекты. Этому субъекту трудно сказать, что будет через месяц, не говоря уже о том, где он(а) будет находиться через год. Для них не имеет смысла строить долгосрочные профессиональные карьеры и делать значительные инвестиции в расчете на отложенную прибыль. Быстрый, пусть и небольшой доход, надежнее и актуальнее, нежели отложенный. Мобильный субъект предпочтет работу временную, соответствующую его/ее образу жизни, которую легко оставит в пользу дальнейшего передвижения.

Накопление разных навыков, связанных с местами работы и местами жительства, широким кругом общения, регулярным пересечением разнообразных границ дает основания для формирования множественности идентичностей, позволяет играть ими, актуализировать ту из них, которая наиболее востребована «здесь и сейчас». При этом есть и обратная сторона подобной множественности - своего рода отчуждение и избегание устойчивых идентичностей или лояльностей, в частности, связанных с местом работы. Множественность идентичностей дает основания для множественных солидарностей в трудовой сфере. Так, Рахмонбек легко и быстро меняет работодателей и партнеров вне зависимости от их этничности и места происхождения. Безусловно, общий язык, поделенный опыт и образ жизни могут стать основаниями для солидарности, однако для аккумуляции и взаимного дополнения имеющихся капиталов партнером по бизнесу может стать, скажем, местный житель.

Как показывает исследование, трудовые траектории мигрантов не представляют собой линейную карьеру как целенаправленное движение в рамках 
одной профессии или одной организации. Карьера мобильного субъекта экстенсивна - мигрант накапливает самые разнообразные опыты, меняя места работы и профессиональные сферы, сочетая разные формы занятости. Такая «копилка» становится капиталом, именно разные навыки могут быть востребованы в различных ситуациях и контекстах, в которых может оказаться или даже обнаружить себя мигрант (например, при изменении миграционного законодательства). Отчасти такая карьера вписывается в концепцию портфельной карьеры (Cohen, Mallon 1999; Handy 1992), выступающей альтернативой организационной карьере. Она не иерархична и представляет собой «портфель» профессиональных опытов. Для нее характерны нелинейность, множественность форм, гибкость и неопределенность, но в то же время она позволяет быть всегда востребованными на рынке труда.

В этой связи показателем профессионализма является не сертификат и не стаж работы в той или иной сфере. Ответы на вопросы о том, где, в каких организациях и местах, когда и в каком качестве, как долго работал мигрант, могут стать интегративным показателем его профессионализма, учитывающим общую мобильность субъекта. И в данном случае мигрантский стаж оказывается важнее профессионального. Безусловно, множественность накопленных опытов не тождественна профессионализму в конкретной сфере. И именно здесь обнаруживаются напряжения и конфликты, связанные с разным представлением о профессионализме между работодателем и работником или между поставщиком услуг и их получателем.

\section{Прекарность мобильного субъекта}

По мнению исследователей феномена прекарности в российском обществе, «у трудовых мигрантов сформированы черты и характеристики, указывающие на их прекарное положение», среди которых «неустойчивое социальное положение, усеченный социальный статус, негарантированная занятость, потеря профессиональной идентичности, депрофессионализация, социальная незащищенность» (Воробьева 2020: 272). Все эти характеристики мы отмечали в наших исследованиях. Однако, полагаю, анализировать ситуацию прекарности мигрантов необходимо не из перспективы седентаризма, но мобильности.

Временная и неполная занятость связана не только с особыми структурными условиями, социально-экономическими и правовыми контекстами, в которых оказываются мигранты, но является сознательным выбором и стратегией расширения поля деятельности, желанием «не класть яйца в одну корзину» и реализовать себя максимально широко, ибо множественность и подвижность- основные сущностные характеристики мобильного субъекта. Переход от постоянных гарантированных трудовых отношений к нестабильным формам занятости, можно интерпретировать как избегание и даже сознательный уход от любых устойчивых, связывающих отношений. 
Большинство информантов рассказывали, как они легко увольняются в ситуации, когда им необходимо уехать домой, особенно если срок поездки не определен. Зачастую мигранты пытаются «зарезервировать» за собой рабочее место, предложив его своим знакомым, но по разным причинам они не всегда возвращаются на прежнее место работы. Для работодателя такая ситуация выглядит как «бесконечный круговорот» рабочей силы, в профессионализацию и повышение квалификации которой вкладывать не эффективно.

Потеря собственной профессиональной идентичности и депрофессионализация, безусловно, имеет место в среде мигрантов. Однако мои информанты не интерпретируют ситуацию как утрату и практически не проблематизируют ее, акцентируя внимание на приобретении новых профессиональных опытов, которые могут быть востребованы в любой момент в принимающей стране или при возвращении домой. Мигрируя они перемещаются в класс низкоквалифицированных и малооплачиваемых работников, однако проблемы снижения социального статуса не столь очевидны и однозначны, как может показаться на первый взгляд. Современные мигранты- это трансмигранты, которые «живут одновременно в двух и более обществах» (Glick Schiller et al. 1992), находятся в нескольких рамках референций, будучи одновременно «своими» и «чужими», «законными» и «незаконными», «семейными» и «несемейными», «бедными» и «богатыми» и пр. (Абашин 2012: 10). Статус мигранта в стране исхода или в среде таких же трудовых мигрантов может отличаться и отличается от статуса в принимающем обществе. Система координат мобильного субъекта предлагает свою иерархию статусов.

Отдельно стоит обсудить практически полное отсутствие социальнотрудовых прав мигрантов, их социальную незащищенность и уязвимость. Информанты часто рассказывали об обманах, низкой и нестабильной заработной плате, о невозможности уйти в оплачиваемый отпуск, о требованиях работать без выходных, о бесконечном изменении и расширении трудовых обязанностей. В большинстве случаев мигранты практически не знают содержания трудовых договоров, которые заключаются при найме на работу, о возможностях защитить свои права. Однако этот факт вызван не только и не столько правовой неграмотностью или исключенностью из новой для них правовой системы трудовых отношений. Зачастую, информанты сознательно избегали формализации в трудовой сфере, переводя отношения в пространство неформального с тем, чтобы избежать долгосрочных обязательств, становящихся бременем для мобильного субъекта.

\section{Заключение}

В исследовании трудовой активности мигрантов я сменила седентаристскую оптику на мобильную. Исходя из этой перспективы, проанализированы 
трудовые траектории мигрантов из Средней Азии: введен концепт «мобильного субъекта», среди специфических черт которого- подвижность и нестабильность, множественность жизненных проектов, жизнь в «сиюминутном» времени, автономизация и отказ от интеграции.

Трудовые биографии мигрантов не линейны и вариативны. Как правило, мигранты трудятся в нескольких местах, сочетают разные формы занятости, реализуют себя в рамках разных профессиональных сфер. Профессиональная карьера мобильного субъекта- это накопление различных профессиональных навыков в разных сферах, что позволяет реактивно приспосабливаться к меняющемуся рынку труда и подвижным структурным условиям, однако спектр возможностей ограничен низкоквалифицированным трудом.

Полагаю, что смена оптики позволяет иначе взглянуть на мигрантский труд и увидеть в нем не только проблемы, зависимость, эксплуатацию, но и субъектность мигрантов в выборе трудовых стратегий. Нестабильность и прекарность труда мигрантов встроена в понятие мобильного субъекта, является его конституирующей чертой. В этой связи для лучшего понимания данного феномена его следует рассматривать в перспективе мобильности.

\section{Выражение признательности}

Статья подготовлена на материалах, собранных в рамках проекта «Транснациональные и транслокальные аспекты миграции» (грант РНФ № 14-18-02149, 14-18-02149П, 2014-2018). Проект реализован в Европейском университете в Санкт-Петербурге под руководством проф. С. Абашина.

\section{Список источников}

Абашин С. (2012) Среднеазиатская миграция: практики, локальные сообщества, транснационализм. Этнографическое обозрение, (4): 3-13.

Бауман 3. (2008) Текучая современность. СПб.: Питер.

Бредникова О. (2017) (Не)возвращение: могут ли мигранты стать бывшими? Этнографическое обозрение, (3): 32-47.

Бредникова О., Ткач О. (2010) Дом для номады. Laboratorium: журнал соииальных исследований, 2 (3): 72-95.

Бредникова О., Паченков О. (2002) Этничность «этнической экономики» и социальные сети мигрантов. Экономическая сочиология, 3 (2): 74-81.

Воробьева И. (2020) Труд мигантов в России: декларации и реальность. Ж. Тощенко (ред.) Прекариат: становление нового класса. М.: Центр социального прогнозирования и маркетинга:262-283.

Кастельс М. (2000) Информационная эпоха: экономика, общество и культура. М.: ГУ ВШЭ. 
Пешкова В. (2018) Предпринимательство мигрантов в России: структурные возможности. Власть, (1): 107-115.

Уолдингер Х., Олдрич Р., Уорд Р. (2008) Этнические предприниматели. Экономическая соииология, 9 (5): $30-55$.

Урри Д. (2012) Сочиология за пределами обществ: виды мобильности для ХХІ столетия. М.: Изд. дом Высшей школы экономики.

Цапко М. (2020) Самозанятость. Ж. Тощенко (ред.) Прекариат: становление нового класса. М.: Центр социального прогнозирования и маркетинга:229-231.

Benson M., O'reilly K. (2009) Migration and the Search for a Better Way of Life: A Critical Exploration of Lifestyle Migration. Sociological Review, 57 (4): 608-625.

Biao X. (2007) The Making of Mobile Subjects: How Migration and Institutional Reform Intersect in Northeast China. Dialogue, 50 (4): 69-74.

Breckner R. (2014) Collective Identities in Migration: Biographical Perspectives on Ambivalences and Paradoxes. Sociology and Anthropology, 2 (1): 15-24.

Cohen L., Mallon M. (1999) The Transition from Organisational Employment to Portfolio Working: Perceptions of 'Boundarylessness'. Work, Employment and Society, 13 (2):329-352.

Deleuze G., Guattari F. (1986) Nomadology: The War Machine. New York: Semiotext(e).

Edwards P., Ram M., Jones T., Doldor S. (2016) New Migrant Businesses and Their Workers: Developing, but not Transforming, the Ethnic Economy. Ethnic and Racial Studies, 39 (9): 1587-1617.

Glick Schiller N.G., Basch L., Blanc-Szanton C. (1992) Transnationalism: A New Analytic Framework for Understanding Migration. N. Glick Schiller, L. Basch, C. Blanc-Szanton (eds.) Towards a Transnational Perspective on Migration: Race, Class, Ethnicity, and Nationalism Reconsidered. New York: New York Academy of Sciences: 1-24.

Handy C.B. (1992) The Future of Work. Oxford: Blackwell.

Kalčić Š. (2013) Going Nomad: New Mobile Lifestyles among Europeans. Two Homelands, (38): 33-48.

Light I., Gold S. (2000) Ethnic Economies. New York: Academic Press.

Nuade W., Siegel M., Marchand K. (2017) Migration, Entrepreneurship and Development: Critical Questions. IZA Journal of Migration, 6 (1): 1-16.

Slany K., Kontos M., Liapy M. (eds.) (2010) Women in New Migrations: Current Debates in European Societies. Cracow: Jagiellonian University Press.

Vertovec S. (2007) Introduction: New Directions in the Anthropology of Migration and Multiculturalism. Ethnic and Racial Studies, 30 (6):961-978. 
Olga Brednikova

\section{MOBILE EMPLOYMENT OF A MOBILE SUBJECT}

This article analyses the labour trajectories of migrants from Central Asia who have come to Russia's largest cities for work. The study offers a contrasting perspective to more sedentary analysis by interpreting the activities of migrant workers through the concept of mobility. For this purpose, I introduce the notion of the 'mobile subject', whose specific features include movement, instability, multiplicity of life projects, planning in 'momentary time', autonomy and rejection of integration. The research was carried out with the use of a qualitative methodology focusing on thirty biographies of migrants observed over an extended period of time. The text examines three cases. Due to structural restrictions at their new place of residence, migrants tend to occupy niche low-skilled labour. By changing national contexts, a mobile subject often starts his or her working career from scratch, without using previous qualifications. According to this research, working migrants are employed in more than one place at the same time; they operate in different professional fields; combine different forms of employment; are not tied to the same job. Migrant labour trajectories do not represent a linear career within a single profession or organisation. The career of a mobile subject is extensive as a migrant accumulates a variety of experiences by changing places of work and professional spheres, which allow them to be mobile, to reactively adapt to the changing labour market and changing structural conditions. The change in interpretative lens to mobile subjectivity in this artcle offers a new perspective in the understanding of migrant labour and makes it possible to see not only the problems (precarity, instability, (self-) exploitation) but also the agency of migrants in choosing of labour strategies.

Key words: mobile subject, migration from Central Asia, life trajectories, labour career and labour strategies, precarity

DOI: $10.17323 / 727-0634-2020-18-4-705-720$

\section{References:}

Abashin S. (2012) Sredneaziatskaya migraciya: praktiki, lokal'nye soobshchestva, transnacionalizm [Central Asian Migration: Practices, Local Communities, Transnationalism]. Etnograficheskoe obozrenie [Ethnographic Review], (4):3-13.

Bauman Z. (2008) Tekuchaya sovremennost' [Liquid Modernity]. St. Petersburg: Piter.

Benson M., O'reilly K. (2009) Migration and the Search for a Better Way of Life: A Critical Exploration of Lifestyle Migration. Sociological Review, 57 (4): 608-625.

Olga Brednikova - PhD (Kandidat Nauk) in Sociology, Research Fellow, Centre for Independent Social Research, St. Petersburg, Russian Federation. Email: brednikova@cisr.ru 
Biao X. (2007) The Making of Mobile Subjects: How Migration and Institutional Reform Intersect in Northeast China. Dialogue, 50 (4): 69-74.

Breckner R. (2014) Collective Identities in Migration: Biographical Perspectives on Ambivalences and Paradoxes. Sociology and Anthropology, 2 (1): 15-24.

Brednikova O. (2017) (Ne)vozvrashchenie: mogut li migranty stat' byvshimi? [(Non)return: Can Migrants Become Ex-migrants?]. Etnograficheskoe obozrenie [Ethnographic Review], (3): 32-47.

Brednikova O., Pachenkov O. (2002) Etnichnost' 'etnicheskoj ekonomiki' i social'nye seti migrantov [The Ethnicity of 'Ethnic Economy' and the Social Networks of Migrants]. Ekonomicheskaya sociologiya [Economic Sociology], 3 (2): 74-81.

Brednikova O., Tkach O. (2010). Dom dlya nomady [What Home Means to the Nomad]. Laboratorium, 2 (3): 72-95.

Capko M. (2020) Samozanyatost' [Self-employment]. In: Toshchenko Z. (ed.) Prekariat: stanovlenie novogo klassa [Precariat. Starting a New Class]. Moscow: Centr social'nogo prognozirovaniya i marketinga: $229-231$.

Castells M. (2000) Informacionnaya epoha: ekonomika, obshchestvo i kul'tura [The Information Age: Economy, Society and Culture]. Moscow: HSE.

Cohen L., Mallon M. (1999) The Transition from Organisational Employment to Portfolio Working: Perceptions of 'Boundarylessness'. Work, Employment and Society, 13 (2):329-352.

Deleuze G., Guattari F. (1986) Nomadology: The War Machine. New York: Semiotext(e).

Edwards P., Ram M., Jones T., Doldor S. (2016) New Migrant Businesses and Their Workers: Developing, but not Transforming, the Ethnic Economy. Ethnic and Racial Studies, 39 (9): 1587-1617.

Glick Schiller N. G., Basch L., Blanc-Szanton C. (1992) Transnationalism: A New Analytic Framework for Understanding Migration. In: N. Glick Schiller, L. Basch, C. BlancSzanton (eds.) Towards a Transnational Perspective on Migration: Race, Class, Ethnicity, and Nationalism Reconsidered. New York: New York Academy of Sciences: 1-24.

Handy C. B. (1992) The Future of Work. Oxford: Blackwell.

Kalčić Š. (2013) Going Nomad: New Mobile Lifestyles among Europeans. Two Homelands, (38): 33-48.

Light I., Gold S. (2000) Ethnic Economies. New York: Academic Press.

Nuade W., Siegel M., Marchand K. (2017) Migration, Entrepreneurship and Development: Critical Questions. IZA Journal of Migration, 6 (1): 1-16.

Peshkova V. (2018) Predprinimatel'stvo migrantov v Rossii: strukturnye vozmozhnosti [The Entrepreneurship of Migrants in Russia: Structural Capacity]. Vlast' [Power], (1): 107-115.

Slany K., Kontos M., Liapy M. (eds.) (2010) Women in New Migrations: Current Debates in European Societies. Cracow: Jagiellonian University Press.

Urry J. (2012) Sociologiya za predelami obshchestv: vidy mobil'nosti dlya XXI stoletiya [Sociology Beyond Society: Mobilities for the XXI Century]. Moscow: HSE. 
Vertovec S. (2007) Introduction: New Directions in the Anthropology of Migration and Multiculturalism. Ethnic and Racial Studies, 30 (6): 961-978.

Vorob'eva I. (2020) Trud migantov v Rossii: deklaracii i real'nost' [Migrant Labour in Russia. Declarations and Reality]. In: Toshchenko Zh. (ed.) Prekariat: stanovlenie novogo klas$s a$ [Precariat. Starting a New Class]. Moscow: Centr social'nogo prognozirovaniya i marketinga: 262-283.

Waldinger R., Aldrich H., Ward R. (2008) Etnicheskie predprinimateli [Ethnic Entrepreneurs]. Ekonomicheskaya sociologiya [Economic Sociology], 9 (5):30-55. 